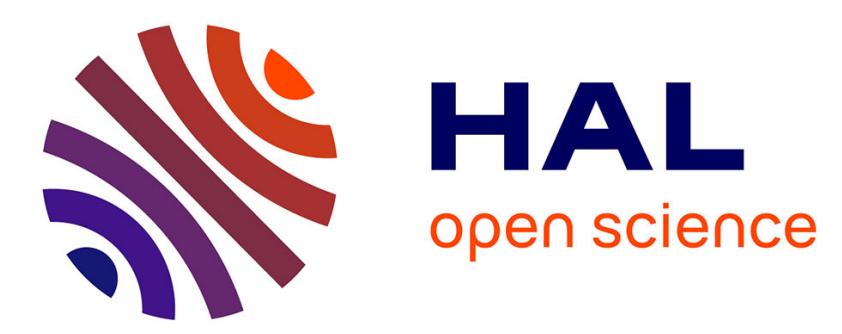

\title{
Association between breast milk fatty acids and HIV-1 transmission through breastfeeding
}

Stéphanie Badiou, E. Tuaillon, J. Viljoen, J.B. Escudié, Jean-Paul Cristol, M.L. Newell, P. van de Perre, D. Neveu

\section{- To cite this version:}

Stéphanie Badiou, E. Tuaillon, J. Viljoen, J.B. Escudié, Jean-Paul Cristol, et al.. Association between breast milk fatty acids and HIV-1 transmission through breastfeeding. Prostaglandins, Leukotrienes and Essential Fatty Acids, 2016, 105, pp.35 - 42. 10.1016/j.plefa.2015.11.004 . hal-01803024

\section{HAL Id: hal-01803024 \\ https://hal.umontpellier.fr/hal-01803024}

Submitted on 29 Nov 2019

HAL is a multi-disciplinary open access archive for the deposit and dissemination of scientific research documents, whether they are published or not. The documents may come from teaching and research institutions in France or abroad, or from public or private research centers.
L'archive ouverte pluridisciplinaire HAL, est destinée au dépôt et à la diffusion de documents scientifiques de niveau recherche, publiés ou non, émanant des établissements d'enseignement et de recherche français ou étrangers, des laboratoires publics ou privés. 


\section{Association between breast milk fatty acids and HIV-1 transmission through breastfeeding}

S. Badiou ${ }^{\mathrm{a}, \mathrm{b}, *}$, E. Tuaillon $^{\mathrm{c}, \mathrm{d}}$, J. Viljoen ${ }^{\mathrm{e}}$, J.B. Escudié ${ }^{\mathrm{d}}$, J.P. Cristol ${ }^{\mathrm{a}, \mathrm{b}}$, M.L. Newell ${ }^{\mathrm{f}}$, P. Van de Perre ${ }^{\text {c,d }}$, D. Neveu ${ }^{\mathrm{d}}$

a Department of Biochemistry, CHU Montpellier, University of Montpellier, France

b PhyMedExp, University of Montpellier, INSERM U1046, CNRS UMR 9214, 34295 Montpellier Cedex 5, France

${ }^{\mathrm{C}}$ Department of Bacteriology and Virology, CHU Montpellier, University of Montpellier, France

d INSERM U 1058, Infection by HIV and by Agents with Mucocutaneous Tropism: From Pathogenesis to Prevention, University of Montpellier, France

${ }^{\mathrm{e}}$ Africa Centre for Health and Population Studies, University of KwaZulu-Natal, South Africa

${ }^{\mathrm{f}}$ Human Development and Health, Faculty of Medicine, University of Southampton, Southampton General Hospital, Tremona Road, Southampton SO16 6YD,

United Kingdom

Keywords:

Fatty acids n-3 n-7

Breast milk

HIV

Mother-to-child transmission

Breastfeeding

Cytokines

Immune factors

\begin{abstract}
A B S T R A C T
A residual mother-to-child transmission of HIV through breastfeeding persists despite prophylaxis. We identified breast milk fatty acids (FA) associated with postnatal HIV transmission through breastfeeding in a case-control study. Cases $(n=23)$ were HIV-infected women with an infant who acquired HIV after 6 weeks of age. Controls $(n=23)$ were matched on infant's age at sample collection. Adjusting for maternal antenatal plasma CD4 T cell count, cis-vaccenic acid (18:1n-7) and eicosatrienoic acid (20:3n-3) were associated with HIV transmission in opposite dose-response manner: OR (tertile 3 versus tertile 1): 10.8 and $0.16, p$ for trend $=\mathbf{0 . 0 2}$ and $\mathbf{0 . 0 3}$, respectively. These fatty acids correlated with HIV RNA load, $\mathrm{T}$ helper-1 related cytokines, IL15, IP10, and $\beta 2$ microglobulin, positively for cis-vaccenic acid, negatively for eicosatrienoic acid. These results suggested a change in FA synthesis by mammary gland cells leading to increased cis-vaccenic acid in milk of mothers who transmitted HIV to their infant during breastfeeding.
\end{abstract}

\section{Introduction}

The 2013 WHO guidelines recommend that HIV-infected mothers breastfeed their infants for the first 6 months of life, introducing appropriate complementary foods thereafter, and continue breastfeeding for the first 12 months, with prophylactic antiretroviral therapy delivered to the mother and a short prophylactic course to the infant [1]. However, there is a residual postnatal mother-to-child transmission (MTCT) of HIV through breastfeeding despite prophylaxis [2,3]. Identifying the role of breast milk components in HIV MTCT through breastfeeding would add to the scientific knowledge base for clinical practice and prevention of postnatal HIV transmission.

Human breast milk is a complex body fluid containing compounds with immunological, antibacterial and antiviral functions [4]. In vivo experiments have shown that whole human breast milk

* Corresponding author at: Department of Biochemistry, CHU Montpellier, 371 av doyen Gaston Giraud, F34295 Montpellier Cedex 5, France. Tel.: 33467338315.

E-mail address: s-badiou@chu-montpellier.fr (S. Badiou). inhibits oral transmission of cell-free or cell-associated HIV-1 in humanized bone marrow/liver/thymus mice [5]. In vitro experiments have also shown that skim human breast milk inhibits cellfree HIV-1 infection but not cell-associated HIV-1 infection of $\mathrm{CD} 4+\mathrm{T}$ cells [6]. These findings suggest that the lipid fraction of breast milk contains inhibitors of cell-associated and/or cell-free HIV that may both be associated with postnatal MTCT of HIV $[7,8]$. Interestingly, Villamor et al. have shown that long chain polyunsaturated fatty acids (LC-PUFA) of the $n-6$ family in breast milk are associated with a lower risk of postnatal transmission of HIV and a lower level of breast milk HIV RNA [9]. However, this study did not investigate the relationship of PUFA with breast milk immune components.

Beyond nutritional and developmental functions, human milk is involved in the modulation of inflammation and immune response. LC-PUFA acts as lipid mediators that regulate inflammation: prostaglandins and leukotrienes derived from either $n-6$ or n-3 LC-PUFA, resolvins or protectins derived only from n-3 LC-PUFA [10]. A beneficial anti-inflammatory profile is recognized for the $n-3$ family while the $n-6$ family is more likely associated 
with inflammatory effects [11]. Breast milk contains also several cytokines with pro-inflammatory effect such as IL-1 $\beta$, IL-6, TNF- $\alpha$, and IFN- $\gamma$ and cytokines of the CXC and CC chemokine family such as IL-8, monocyte chemotactic protein-1 (MCP-1), RANTES and macrophage inflammatory protein-1a (MIP-1a). Cytokines of breast milk are transcribed and secreted by both mammary epithelial cells and breast milk leukocytes [12]. Previous data reported a relationship between breast milk cytokines and FA composition [13], in agreement with the recognized immune and inflammatory modulating functions of FA. Although the FA profile in breast milk could be one factor driving immune activation observed in breast milk, no study determined the relationship between breast milk FA composition and cytokines levels in regard to a mother-to-child transmission (MTCT) of HIV through breastfeeding.

The present study aimed as first objective to identify breast milk fatty acids (FA) associated with postnatal transmission of HIV through breastfeeding and to determine as second objective the associations of FA with inflammatory and immune factors and with HIV RNA load, in breast milk.

\section{Subjects and methods}

In 2008, we nested a case-control study in a large infant feeding intervention cohort (Vertical Transmission Study) of women attending 9 clinics ( 8 rural and 1 urban) in KwaZulu-Natal, South Africa. The Vertical Transmission Study aimed to examine HIV transmission by breastfeeding in a community with a high prevalence of HIV infection [14,15]. Single-dose nevirapine was provided to all HIV-1 infected women and their infant peripartum as prevention of MTCT prophylaxis. Breast milk samples from mothers and dried blood spot samples from infants were collected at 6 weeks after delivery and monthly thereafter; an additional dried blood spot sample was taken from infants within $72 \mathrm{~h}$ of delivery when possible $[14,15]$. Postnatal transmission was defined as infant's HIV infection acquired after the age 6 weeks. The estimated age at HIV-1 infection in infant was taken as the midpoint between the last negative RNA polymerase chain reaction (PCR) result and the first positive RNA PCR result [15]. Cases were HIVinfected women with a postnatally HIV-infected infant ("PP" group, $n=23$ women). Controls were HIV-infected women with a HIV-uninfected infant ("PN" group, $n=23$ women). A second control group was constituted with HIV-uninfected mothers ("NN" group, $n=23$ women) for comparison of the impact of HIV status on milk FA composition. Controls were matched for infant age at the time of obtainment of breast milk samples that was closest to a postnatally HIV-infected infants' age at last negative PCR result (in a 1:1:1 ratio). The minimum infant's age at HIV infection was 49.5 days. For this study, we selected women with fatty acids, immune and inflammatory soluble factors, and HIV RNA load quantified in breast milk as well with antenatal plasma HIV RNA load and CD4 cell count documented. Breast milk including the lipid fraction was collected from stored $\left(-80^{\circ} \mathrm{C}\right)$ whole breast milk samples. RNA was isolated from $500 \mu \mathrm{L}$ of lactoserum with the magnetic particle-based ASPS method (Abbott), and HIV load was quantified using the HIV Charge Virale assay (Biocentric) on the MJ MiniOpticon quantitative PCR detection platform (Biorad), with a lower detection limit of 375 copies per $\mathrm{mL}$ of lactoserum [16]. This method enabled accurate assessment of cell-free viral load that is preferentially entrapped by lipids [17].

\subsection{Biochemical analyses}

Total cholesterol and triglycerides levels were quantified (April 2009 to December 2009) in whole milk with adaptation of 
Maternal and infant characteristics of HIV-infected mothers with infected or uninfected infant and HIV-uninfected mothers.

\begin{tabular}{|c|c|c|c|c|c|c|c|}
\hline & \multicolumn{2}{|c|}{ HIV-uninfected mother } & \multicolumn{4}{|c|}{ HIV infected mother } & \multirow[b]{3}{*}{$p$ Value } \\
\hline & \multirow[b]{2}{*}{$n$} & \multirow[b]{2}{*}{ Median [Q1;Q3] } & \multicolumn{2}{|c|}{ HIV-uninfected infant } & \multicolumn{2}{|c|}{ HIV-infected infant } & \\
\hline & & & $n$ & Median [Q1;Q3] & $n$ & Median [Q1;Q3] & \\
\hline \multicolumn{8}{|l|}{ Maternal characteristics } \\
\hline Age at delivery, years & 23 & $21.5[19.8 ; 26.4]$ & 23 & $25.5[20.6 ; 30.4]$ & 23 & $26.4[22.4 ; 28.2]$ & 0.13 \\
\hline Enrollment clinic, $n(\%)$ & 23 & & 23 & & 23 & & 0.07 \\
\hline Peri-urban & & $5(22)$ & & $5(22)$ & & $11(48)$ & \\
\hline Rural & & $16(70)$ & & $11(48)$ & & $8(35)$ & . \\
\hline Urban & & $2(8)$ & & $7(30)$ & & $4(17)$ & . \\
\hline Highest level of education, $n(\%)$ & 23 & & 23 & & 23 & & 0.55 \\
\hline No education & & 0 & & $2(9)$ & & $1(4)$ & \\
\hline Some primary & & $9(39)$ & & $7(30)$ & & $5(22)$ & . \\
\hline Secondary and tertiary & & $13(57)$ & & $13(57)$ & & $17(74)$ & . \\
\hline Do not know & & $1(4)$ & & $1(4)$ & & 0 & . \\
\hline Previous pregnancies, no & 23 & $1[0 ; 2]$ & 23 & $2[0 ; 3]$ & 23 & $1[1 ; 2]$ & 0.57 \\
\hline Antenatal CD4-cell count, cells $/ \mu \mathrm{L}$ & 23 & & 23 & $538[294 ; 673]$ & 23 & $333[176 ; 682]$ & 0.41 \\
\hline Antenatal plasma HIV-1 RNA load, $\log 10$ copies/mL & 23 & NA & 23 & $3.96[3.28 ; 4.34]$ & 23 & $4.49[4.20 ; 4.81]$ & 0.006 \\
\hline CD4-cell count at 6 months post-partum, cells $/ \mu \mathrm{L}$ & 23 & & 23 & $566[323 ; 784]$ & 16 & $342[218 ; 667]$ & 0.09 \\
\hline Plasma HIV-1 RNA load at 6 months post-partum, $\log 10$ copies/mL & 23 & NA & 23 & $4.00[3.32 ; 4.49]$ & 16 & $4.66[3.95 ; 4.83]$ & 0.07 \\
\hline \multicolumn{8}{|l|}{ Infant characteristics } \\
\hline Sex male, $n(\%)$ & 23 & $13(57)$ & 23 & $13(57)$ & 23 & $10(43)$ & 0.59 \\
\hline Birth weight, g & 22 & $3065[3000 ; 3200]$ & 22 & $3100[2900 ; 3300]$ & 23 & $3250[2750 ; 3500]$ & 0.96 \\
\hline Age at last HIV-uninfected test result, day & 23 & $660[485 ; 743]$ & 23 & $458[449 ; 736]$ & 23 & $190[100 ; 285]$ & $<0.001$ \\
\hline Age at first HIV-infected test result, day & & NA & & $\mathrm{NA}$ & 23 & $367[129 ; 493]$ & NA \\
\hline \multicolumn{8}{|l|}{ Breast milk sample characteristics } \\
\hline Age of infant at time of breast milk sample, day & 23 & $160[72 ; 218]$ & 23 & $169[70 ; 190]$ & 23 & $154[69 ; 218]$ & 0.89 \\
\hline Delay between milk sampling and infant HIV-positive test, day & & NA & & NA & 23 & $102[14-227]$ & NA \\
\hline HIV-1 RNA load, $\log 10$ copies/mL & & NA & 23 & $2.27[2.27 ; 2.27]$ & 23 & $3.13[2.27 ; 3.74]$ & $<0.001$ \\
\hline HIV-1 DNA load, $\log 10$ copies/mL & & NA & 8 & $0.48[0.48 ; 0.48]$ & 11 & $3.37[0.48 ; 3.59]$ & 0.047 \\
\hline Sub-clinical mastitis, $n(\%)$ & 23 & $5(22)$ & 23 & $4(17)$ & 23 & $8(35)$ & 0.36 \\
\hline
\end{tabular}

of 2-sided type 1 error and a standard deviation of 0.12 (extracted from Villamor et al. [9]).

Breast milk fatty acids (expressed in \% of total FA), immune and inflammatory soluble factors, and log transformed HIV RNA load were analysed in women who had fatty acids, immune and inflammatory soluble factors, and HIV RNA load quantified in breast milk as well with antenatal plasma HIV RNA load and CD4 cell count documented ( $n=23$ for PP, PN and NN groups, PP, PN, NN). All analyses were carried out on samples collected before or at the last negative PCR result in postnatal HIV-infected infants.

Because there was a significant individual difference for each FA between the two breasts and lipid and cytokine profiles depend on local environment, we did not average measurements from the two breasts. Also, using one breast milk sample per woman allowed adjustment on breast milk factors from the same side. We compared baseline characteristics between the three groups "PP", "PN" and "NN" using the Pearson Chi-2 test or the exact Fisher test for qualitative parameters, the ANOVA or the Kruskal-Wallis nonparametric test for quantitative parameters depending on their distribution. FA percentages (\% of total FA) were compared between the three groups using a linear mixed model that accounted for matching. Correlations between FA percentages (\% of total FA) and breast milk HIV RNA load, or breast milk inflammatory or immune soluble factors that were detected in at least $50 \%$ of the samples were assessed with the Spearman correlation coefficient. To estimate the risk of postnatal MTCT of HIV associated with breast milk FA, we built a conditional logistic regression model and used the PHREG procedure in SAS, version 9.2 (SAS Institute). Because the linear relationship between the logistic regression coefficients and FA covariate expressed in percentage (\% of total FA) was not met, each FA variable was transformed into a categorical one. Three categories defined by tertiles were used because of the sample size.

Models were adjusted for maternal antenatal plasma log transformed HIV RNA load or for maternal antenatal plasma CD4 T cell count with the possible addition of the ipsilateral breast milk $\mathrm{Na}+/ \mathrm{K}+$ ratio if the model was stable. $P$ values for trend were derived from the Wald test for an indicator variable representing the ordinal tertiles of FA that was introduced as a continuous predictor in univariate and multivariable conditional logistic regression models (for the adjusted models). We did not correct for multiple testing in this exploratory study. All analyses were carried out using SAS version 9.2 (SAS Institute).

\section{Results}

\subsection{Sample characteristics}

Among the 23 cases, the median estimated infant age at HIV-1 acquisition was 257.5 days [IQR, 116-437 days] with a last negative PCR test result at a minimum age of 39 days. Eight (35\%) infants got infected before 200 days. The three groups had similar sociodemographic characteristics except for enrollment clinic which was mostly rural for NN mothers and urban or semi-urban for PN and PP mothers. Cases (PP group) had higher antepartum plasma HIV RNA load and tended to have lower postpartum plasma CD4 T cell count, and higher postpartum plasma HIV RNA load. Subclinical mastitis defined as a sodium to potassium ratio $>1$ were similarly distributed among the three groups (Table 1). Breast health problems, particularly serious breast pathologies, were rare (one case) [18].

\subsection{Comparison of breast milk fatty acid between HIV-uninfected and HIV-infected women}

NN and PN groups had similar percentages $(p>0.05)$ of total saturated FA, total MUFA n-7, and total PUFA of n- 6 and n-3 families, in both left and right breasts (Table 2 and Supplementary 
Table 1). Further, percentages of essential FA, linoleic (18:2n-6) and $\alpha$-linolenic (18:3n-3) were similar in both groups $(p>0.05)$, in both breasts. Only the percentage of total n-9 MUFA was higher in the PN than the NN group $(p<0.05$ in left breast, $p<0.01$ in right breast), representing mainly difference in the oleic acid.

\subsection{Comparison of breast milk fatty acids between mothers of} postnatal HIV-infected infant and mothers of HIV-uninfected infant

Percentages of each essential FA, linoleic and $\alpha$-linolenic, were similar between PN and PP groups. (Table 2 and Supplementary Table 1). The PP group had significantly higher total MUFA n-7 than PN groups but similar total MUFA n-9. Higher percentage of cis-vaccenic acid (18:1n-7) in PP group compared to PN was observed although similar levels of $16: 1 \mathrm{n}-7$ and of $16: 0$. By contrast lower percentage of stearic acid (18:0) was observed in PP group compared to PN but similar levels of oleic acid (18:1n9). In addition, significant higher arachidonic acid (20:4n-6) percentage in PP than the PN group was noted in both left and right breasts (Table 2 and Supplementary Table 1 ). The PP group tended to have lower percentage of eicosatrienoic acid (20:3n-3) than the PN group.

\subsection{Odds ratio for postnatally HIV transmission through breast-}

feeding according to fatty acids tertile

Table 3 and Supplementary Table 2 show the odds ratios for postnatally HIV transmission through breastfeeding according to fatty acids tertiles, in left and right breast, respectively. Only FA that differ between PP and PN groups or FA involved in the metabolism of these latter are presented. After adjustment for antenatal plasma CD4 T cell count, cis-vaccenic acid percentage was associated with a statistically higher risk of HIV transmission in a significant dose-response relationship while eicosatrienoic acid (18:3n-3) was associated with a lower risk of HIV transmission in a dose-response relationship (Table 3), both in left and right breast.

\subsection{Correlations between fatty acids and inflammatory and immune} soluble factors in breast milk

Inflammatory and immune soluble factors detected in more than $50 \%$ of either left or right breast samples in the 46 HIVinfected women were included in further analyzes, namely: IL-2R (63\%), IL-12 (100\%), IL-15 (78\%), IP-10 (100\%), MIG (93\%), IL-7 (67\%), MIP- $1 \alpha(71 \%)$, MCP-1 (99\%), MIP-1 $\beta$ (75\%), IL-1RA (88\% of samples), IL-8 (100\%), RANTES ( $81 \%), \beta 2$ microglobulin (100\%) and CRP (94\%). Using left breast samples, cis-vaccenic acid percentage was associated with breast milk HIV RNA load as well as with concentration of $\beta 2$ microglobulin, IL-15, IP-10, and $\mathrm{Na}+/ \mathrm{K}+$ ratio. The eicosatrienoic acid (20:3n-3) percentage was inversely correlated with concentration of $\beta 2$ microglobulin, IL-15, IP-10, RANTES, IL-7, and with $\mathrm{Na}+/ \mathrm{K}+$ ratio in breast milk (Table 4). Results were similar if right breast samples were analyzed (Supplementary Table 3). Additional adjustment for breast milk $\mathrm{Na}+/ \mathrm{K}+$ ratio to maternal antenatal plasma CD4 $+\mathrm{T}$ cell did not change the significant dose-response relationship of the risk of HIV-1 transmission associated with cis-vaccenic acid $\left(\mathrm{OR}_{\text {adjusted }}\right.$ : second tertile versus first tertile: 1.99 [0.37;10.72]; third tertile versus first tertile:10.1 [1.17;87.12]; $p$ for trend: 0.025 ) or with 11,14,17-eicosatrienoic acid ( $\mathrm{OR}_{\text {adjusted: }}$ second tertile versus first tertile: 0.58 [0.07;4.6] third tertile versus first tertile: 0.17 [0.02;1.51]; $p$ for trend: 0.043 ) using left breast samples. Comparison of immune factors correlated to cis-vaccenic acid and/or eicoastrienoic acid between PN and PP groups were presented in Supplementary Table 4.
Table 2

Distribution of fatty acids (\% of total fatty acid) in breast milk among HIV-1 uninfected mothers and HIV-1 infected mothers with an uninfected or an infected infant (left breast samples).

\begin{tabular}{|c|c|c|c|c|}
\hline & \multirow{2}{*}{$\begin{array}{l}\text { HIV-uninfected } \\
\text { mother (NN, } \\
n=23)\end{array}$} & \multicolumn{2}{|c|}{ HIV-infected mother } & \multirow[b]{2}{*}{$p$ Value } \\
\hline & & $\begin{array}{l}\text { HIV-uninfected } \\
\text { infant }(\mathrm{PN} \text {, } \\
n=23)\end{array}$ & $\begin{array}{l}\text { HIV-infected } \\
\text { infant (PP, } \\
n=23 \text { ) }\end{array}$ & \\
\hline Fatty acid & Median [Q1; Q3] & Median [Q1; Q3] & $\begin{array}{l}\text { Median [Q1; } \\
\text { Q3] }\end{array}$ & PN vs PP \\
\hline $12: 0$ & $6.8[4.5 ; 9.3]$ & $7.5[5.7 ; 8.8]$ & $6.9[4.6 ; 7.9]$ & 0.29 \\
\hline 14:0 & $12.1[10.0 ; 15.3]$ & $10.0[8.55 ; 12.9]$ & $11.0[7.49 ; 14.2]$ & 0.94 \\
\hline 15:0 & $0.19[0.14 ; 0.33]$ & $0.2[0.16 ; 0.29]$ & $0.17[0.15 ; 0.21]$ & 0.24 \\
\hline $16: 0$ & $22.2[20.6 ; 24.0]$ & $20.5[18.9 ; 23.8]$ & $20.3[19.2 ; 22.7]$ & 0.51 \\
\hline 18:0 & $5.3[4.4 ; 7.3]$ & $6.0[5.1 ; 7.6]$ & $5.0[4.4 ; 5.9]$ & 0.009 \\
\hline $20: 0$ & $0.15[0.13 ; 0.23]$ & $0.16[0.13 ; 0.2]$ & $0.13[0.08 ; 0.16]$ & 0.058 \\
\hline $22: 0$ & $0.09[0.05 ; 0.12]$ & $0.05[0.03 ; 0.1]$ & $0.05[0.03 ; 0.08]$ & 0.26 \\
\hline $24: 0$ & $0.04[0 ; 0.08]$ & $0.06[0 ; 0.08]$ & $0.08[0.04 ; 0.2]$ & 0.038 \\
\hline Total SFA & $48.0[43.4 ; 53.5]$ & $46.1[44.2 ; 51.4]$ & $44.4[40.1 ; 48.7]$ & 0.12 \\
\hline $16: 1 n-7$ & $2.1[1.4 ; 2.7]$ & $2.0[1.7 ; 2.5]$ & $2.1[1.8 ; 2.9]$ & 0.25 \\
\hline $\begin{array}{c}18: 1 \mathrm{n}-7 \\
\text { cis }\end{array}$ & $1.3[1.0 ; 1.6]$ & $1.2[1.1 ; 1.4]$ & $1.6[1.4 ; 1.8]$ & 0.002 \\
\hline $20: 1 n-7$ & $0.07[0.04 ; 0.11]$ & $0.03[0.01 ; 0.06]$ & $0.05[0.03 ; 0.17]$ & 0.052 \\
\hline MUFA n-7 & $3.5[2.6 ; 4.4]$ & $3.3[2.8 ; 3.9]$ & $3.8[3.4 ; 5.0]$ & 0.039 \\
\hline $16: 1 n-9$ & $0.33[0.26 ; 0.39]$ & $0.38[0.31 ; 0.41]$ & $0.39[0.33 ; 0.43]$ & 0.6 \\
\hline $\begin{array}{l}18: 1 n-9 \\
\text { cis }\end{array}$ & $21.7[18.1 ; 24.8]$ & $23.8[21.8 ; 25.9]$ & $24.4[20.6 ; 26.8]$ & 0.91 \\
\hline $20: 1 n-9$ & $0.26[0.22 ; 0.34]$ & $0.3[0.25 ; 0.35]$ & $0.27[0.04 ; 0.39]$ & 0.067 \\
\hline MUFA n-9 & $22.3[18.6 ; 25.5]$ & $24.4[22.5 ; 26.6]$ & $24.9[21.0 ; 27.2]$ & 0.94 \\
\hline $\begin{array}{l}\text { Total } \\
\quad \text { MUFA }\end{array}$ & $26.0[21.0 ; 29.8]$ & $27.6[24.7 ; 31.1]$ & 29.8 [23.7;31.6] & 0.57 \\
\hline $18: 3 n-3$ & $0.83[0.55 ; 1.12]$ & $0.76[0.51 ; 1.06]$ & $0.79[0.55 ; 0.97]$ & 0.48 \\
\hline $20: 3 n-3$ & $0.08[0.03 ; 0.13]$ & $0.08[0.04 ; 0.12]$ & $0.04[0.01 ; 0.07]$ & 0.13 \\
\hline $20: 5 n-3$ & $<0.01$ & $<0.01$ & $<0.01$ & \\
\hline $22: 5 n-3$ & $0.17[0.13 ; 0.22]$ & $0.13[0.11 ; 0.17]$ & $0.16[0.13 ; 0.19]$ & 0.43 \\
\hline $22: 6 n-3$ & $0.29[0.19 ; 0.46]$ & $0.21[0.15 ; 0.37]$ & $0.26[0.2 ; 0.33]$ & 0.99 \\
\hline PUFA n-3 & $1.4[1.1 ; 1.9]$ & $1.4[1.0 ; 1.6]$ & $1.3[1.1 ; 1.6]$ & 0.71 \\
\hline $\begin{array}{l}18: 2 n-6 \\
\text { cis }\end{array}$ & 22.4 [17.6;25.5] & $19.7[18.5 ; 24.7]$ & 23.6 [18.4;25.3] & 0.37 \\
\hline $\begin{array}{l}18: 3 n-6 \\
\text { cis }\end{array}$ & $0.15[0.09 ; 0.2]$ & $0.12[0.08 ; 0.17]$ & $0.13[0.11 ; 0.16]$ & 0.77 \\
\hline $20: 2 n-6$ & $0.5[0.37 ; 0.61]$ & $0.4[0.32 ; 0.48]$ & $0.41[0.34 ; 0.54]$ & 0.94 \\
\hline $20: 3 n-6$ & $0.52[0.39 ; 0.67]$ & $0.41[0.3 ; 0.51]$ & $0.45[0.38 ; 0.51]$ & 0.47 \\
\hline $20: 4 n-6$ & $0.64[0.53 ; 0.74]$ & $0.59[0.51 ; 0.75]$ & $0.7[0.65 ; 0.82]$ & 0.043 \\
\hline $22: 4 n-6$ & $0.08[0.04 ; 0.17]$ & $0.06[0.03 ; 0.11]$ & $0.06[0.04 ; 0.08]$ & 0.48 \\
\hline PUFA n-6 & $24.4[20.6 ; 27.4]$ & $21.7[20.0 ; 26.5]$ & $25.6[20.1 ; 27.0]$ & 0.34 \\
\hline Total PUFA & $25.5[21.7 ; 29.8]$ & $22.6[20.9 ; 28.0]$ & $26.8[21.3 ; 30.0]$ & 0.34 \\
\hline $\begin{array}{c}18: 1 n-9 \\
\text { trans }\end{array}$ & $0.31[0.15 ; 0.71]$ & $0.42[0.2 ; 0.92]$ & $0.45[0.27 ; 0.91]$ & 0.37 \\
\hline $\begin{array}{c}18: 2 n-6 \\
\text { trans }\end{array}$ & $0.06[0 ; 0.19]$ & $0.1[0.04 ; 0.19]$ & $0.12[0.08 ; 0.24]$ & 0.46 \\
\hline $\begin{array}{l}\text { Total } \\
\text { Trans FA }\end{array}$ & $0.42[0.19 ; 0.9]$ & $0.54[0.27 ; 1.11]$ & $0.61[0.41 ; 1.08]$ & 0.38 \\
\hline
\end{tabular}

Abbreviations: FA: fatty acid; LC long chain; SFA: saturated FA. NN: HIV-1 uninfected mothers; PN: HIV-1 infected mothers with an uninfected infant; PP: HIV-1 infected mothers with an infected infant.

\section{Discussion and conclusion}

In this study, we observed that the relative percentages of two fatty acids in breast milk had opposite dose-response relationships with postnatal HIV-1 transmission by breastfeeding. Cis-vaccenic acid (18:1n-7) was associated with a higher risk of HIV transmission through breastfeeding while eicosatrienoic acid (20:3n-3) was 
Table 3

Odds ratio for HIV transmission through breastfeeding by tertile (T) of fatty acid (\% of total) in left breast milk samples.

\begin{tabular}{|c|c|c|c|c|}
\hline Parameter & $\mathrm{T} 1$ & $\mathrm{~T} 2$ & T3 & $\begin{array}{l}P \text { for } \\
\text { trend }\end{array}$ \\
\hline \multicolumn{5}{|l|}{ 16:0, Palmitic acid } \\
\hline Median \% & 18.36 & 20.25 & 24.27 & \\
\hline PN:PP & $8: 7$ & $6: 9$ & $9: 7$ & 0.86 \\
\hline Adjusted OR [95\%CI] ${ }^{*}$ & 1 & $2.6[0.45 ; 15.3]$ & $0.77[0.18 ; 3.2]$ & 0.84 \\
\hline Adjusted OR [95\%CI] ${ }^{* *}$ & 1 & $2.6[0.4 ; 17.3]$ & $1.4[0.23 ; 8.1]$ & 0.77 \\
\hline \multicolumn{5}{|l|}{ 18:0, Stearic acid } \\
\hline Median \% & 4.09 & 5.5 & 7.0 & \\
\hline PN:PP & $5: 10$ & $7: 8$ & $11: 5$ & 0.082 \\
\hline Adjusted OR $[95 \% \mathrm{CI}]^{*}$ & 1 & $0.69[0.12 ; 3.8]$ & $0.2[0.03 ; 1.2]$ & 0.077 \\
\hline Adjusted OR [95\%CI]** & 1 & $0.92[0.09 ; 9.0]$ & $0.24[0.04 ; 1.4]$ & 0.1 \\
\hline \multicolumn{5}{|l|}{ 16:1n-7, Palmitoleic acid } \\
\hline Median \% & 1.4 & 2.0 & 3.0 & \\
\hline PN:PP & $8: 7$ & $8: 7$ & $7: 9$ & 0.57 \\
\hline Adjusted OR [95\%CI $]^{*}$ & 1 & $1.0[0.27 ; 3.7]$ & $1.6[0.33 ; 8.2]$ & 0.59 \\
\hline Adjusted OR $[95 \% \mathrm{CI}]^{* *}$ & 1 & $1.1[0.24 ; 4.7]$ & $1.31[0.21 ; 8.1]$ & 0.78 \\
\hline \multicolumn{5}{|l|}{ 18:1n-7 cis, Vaccenic acid } \\
\hline Median \% & 1.1 & 1.4 & 1.8 & \\
\hline PN:PP & $12: 3$ & $7: 8$ & $4: 12$ & 0.02 \\
\hline Adjusted OR $[95 \% \mathrm{CI}]^{*}$ & 1 & $2.0[0.37 ; 10.6]$ & $10.8[1.3 ; 91.8]$ & 0.021 \\
\hline Adjusted OR [95\%CI ${ }^{* *}$ & 1 & $2.0[0.32 ; 12.3]$ & $10.1[1.1 ; 93.5]$ & 0.038 \\
\hline \multicolumn{5}{|l|}{$18: 1 n-9$ cis, Oleic acid } \\
\hline Median \% & 19.6 & 23.8 & 27.4 & \\
\hline PN:PP & $8: 7$ & $8: 7$ & $7: 9$ & 0.59 \\
\hline Adjusted OR [95\%CI]* & 1 & $1.1[0.23 ; 4.9]$ & $1.5[0.28 ; 7.6]$ & 0.63 \\
\hline Adjusted OR [95\%CI] ${ }^{* *}$ & 1 & $0.63[0.1 ; 4.0]$ & $0.88[0.17 ; 4.5]$ & 0.97 \\
\hline \multicolumn{5}{|l|}{$\begin{array}{l}\text { 18:3n-3, Alpha-linolenic } \\
\text { acid }\end{array}$} \\
\hline Median \% & 0.495 & 0.75 & 1.115 & \\
\hline PN:PP & $7: 7$ & $8: 8$ & $8: 8$ & 1 \\
\hline Adjusted OR [95\%CI]* & 1 & $0.95[0.14 ; 6.4]$ & $1.01[0.24 ; 4.3]$ & 0.98 \\
\hline Adjusted OR [95\%CI] ${ }^{* *}$ & 1 & $1.23[0.16 ; 9.7]$ & $1.07[0.2 ; 5.7]$ & 0.96 \\
\hline \multicolumn{5}{|l|}{$\begin{array}{l}20: 3 n-3 \text {, Eicosatrienoic } \\
\text { acid }\end{array}$} \\
\hline Median \% & 0.01 & 0.05 & 0.13 & \\
\hline PN:PP & $4: 8$ & $6: 11$ & $13: 4$ & 0.032 \\
\hline Adjusted OR $[95 \% \mathrm{CI}]^{*}$ & 1 & $0.56[0.1 ; 3.2]$ & $0.16[0.02 ; 1.1]$ & 0.032 \\
\hline Adjusted OR [95\%CI] ${ }^{* *}$ & 1 & $0.64[0.09 ; 4.7]$ & $0.13[0.01 ; 1.4]$ & 0.059 \\
\hline \multicolumn{5}{|l|}{ 18:2n-6, Linoleic acid } \\
\hline Median \% & 17.56 & 21.3 & 27.85 & \\
\hline PN:PP & $8: 7$ & $9: 6$ & $6: 10$ & 0.40 \\
\hline Adjusted OR [95\%CI]* & 1 & $0.72[0.17 ; 3.1]$ & $2.08[0.47 ; 9.1]$ & 0.35 \\
\hline Adjusted OR [95\%CI] ${ }^{* *}$ & 1 & $0.13[0.01 ; 1.8]$ & $1.25[0.2 ; 7.7]$ & 0.55 \\
\hline \multicolumn{5}{|l|}{ 20:4n-6, Arachidonic acid } \\
\hline Median \% & 0.51 & 0.68 & 0.82 & \\
\hline PN:PP & $10: 5$ & $8: 7$ & $5: 11$ & 0.11 \\
\hline Adjusted OR $[95 \% \mathrm{CI}]^{*}$ & 1 & $1.51[0.36 ; 6.3]$ & $3.1[0.77 ; 12.4]$ & 0.11 \\
\hline Adjusted OR [95\%CI] ${ }^{* *}$ & 1 & $1.35[0.29 ; 6.2]$ & $1.7[0.38 ; 7.7]$ & 0.49 \\
\hline
\end{tabular}

Abbreviations: PN: HIV-infected mothers with uninfected HIV infant; PP: HIVinfected mothers with infected HIV infant, NA: not applicable because there were too few individuals in a category.

PN:PP: sample size ratio.

OR and their $95 \%$ confidence interval $[95 \% \mathrm{Cl}]$ are derived from conditional logistic regression models with infant HIV status as the dependent variable and independent variables that included indicator variables for T1, T2 and T3 of each fatty acid. $\left({ }^{*}\right)$ Antenatal plasma CD4 T cell count or $\left({ }^{* *}\right)$ antenatal plasma HIV-1 RNA load were adjusted for.

$P$ for trend values are derived from the Wald test for an indicator variable representing the ordinal tertiles of fatty acids that was introduced as a continuous predictor in univariate (for the unadjusted ratio of controls PN to cases PP) and multivariate conditional logistic regression models (for the adjusted models).

associated with a lower risk. In addition, cis-vaccenic acid was associated with a higher cell-free HIV levels in breast milk, and with Th- 1 related cytokines and inflammation markers, while it was the opposite for eicosatrienoic acid (20:3n-3).

Comparison among the three groups of mothers showed that breast milk FA composition differed more according to the infant's HIV status than to the mothers' HIV status (infected or uninfected). Indeed, we observed only a trend to a difference in percentages of oleic acid between HIV-infected and -uninfected mothers while there were significant differences in percentages of stearic, cisvaccenic, and arachidonic acids between transmitting and nontransmitting HIV-infected mothers. Of note, percentages of the two essential FA, linoleic and $\alpha$-linolenic, were similar among the three groups but representation of linoleic acid (about 20\%) were much higher than most of data previously reported [19] while it was the opposite for oleic acid [20]. The percentage of linoleic acid in breast milk depends on diet and transportation from plasma to the mammary gland [20]. The present fatty acid pattern could be related to large intake of vegetable oil such as corn, soybean, sunflower or safflower oils.

In the n-3 FA family, although percentages of the precursor $\alpha$ linolenic were in the range of published data [19], eicosapentaenoic acid (EPA, 20:5n-3) was not detected, in any groups. In human milk, EPA comes from diet, such as fish, and/or transformation of the precursor $\alpha$-linolenic by FA desaturases (Fads) and elongases of very long chain FA (Elovl). Desaturases are encoded by the Fads1, Fads2 and Fads3 genes. Fads1 gene codes for a $\Delta 5$ desaturase while Fads 2 codes for a $\Delta 6$ desaturase and a $\Delta 8$ desaturase [21]. In the present study, we found no detectable EPA without deficiency in $\alpha$-linolenic acid. Interestingly, we detected eicosatrienoic acid (20:3n-3) that can result from $\alpha$-linolenic elongation by Elovl5 [21], as illustrated in Fig. 1A. So, in our study, the first transformation of $\alpha$-linolenic acid appears to be more likely an elongation to form eicosatrienoic acid (20:3n-3) rather than a desaturation that would form stearidonic acid (18:4n-3). Due to common desaturase and elongase activities for $n-6$ and n-3 FA families, it might be assumed that the $\Delta 6$ desaturase activity was mobilized for linoleic acid desaturation, because of its strong representation, at the expense of $\alpha$-linolenic acid. After transformation of $\alpha$-linolenic into eicosatrienoic acid through Elovl5, this latter could be desaturated by the $\Delta 8$ to formeicosatetraenoic acid, the precursor of EPA. Because we detected eicosatrienoic acid without eicosatetraenoic acid and without EPA, it could be considered again that mobilization of $\Delta 8$ for the n-6 pathway could also participate to the specific profile observed in all groups (i.e presence of eicosatrienoic acid but no detection of eicosatetraenoic acid nor of EPA).

To form n-7 FA family, the palmitic acid (16:0) is desaturated by the $\Delta 9$ named stearyl-coA desaturase to be convert in palmitoleic acid (16:1n-7), instead of being elongated by Elovl6 to form stearic acid. Then, palmitoleic acid is elongated into cis-vaccenic acid (18:1n-7) mainly by Elovl5[21] as illustrated in Fig. 1B. Considering that Elovl5 is involved both in eicosatrienoic acid and cis-vaccenic acid formation and that breast milk composition in mothers who transmitted HIV-1 exhibiting higher levels of cis-vaccenic acid but lower levels of eicosatrienoic acid compared to mother who did not, it could be hypothesized that an imbalance of Elovl5 activity occurred between $n-3$ and n-7 pathways.

In addition, transmitting mothers had higher percentages of cis-vaccenic acid in milk than non-transmitting mothers but similar percentages of palmitic and palmitoleic acids. This suggests an effective $\Delta 9$ desaturase activity but an enhanced palmitoleic elongation. It could be also hypothesized that an imbalance between Elovl6 and Elovl5 activities orientate palmitic acid toward cis-vaccenic formation instead of stearic acid formation in transmitting mothers, which is consistent with lower breast milk stearic acid percentages found in this group compared to nontransmitting mothers. Interestingly, cis-vaccenic acid is not only an intermediate of FA synthesis, but acts as a signaling molecule reducing lipogenesis and gluconeogenesis [22, 23]. To our knowledge, no data are available on the relationship between elongase or desaturase activities in milk and HIV-1 transmission through breastfeeding.

Important observation remains the significant association of eicosatrienoic acid (20:3n-3) with a lower risk of HIV MTCT, and 


\begin{tabular}{|c|c|c|c|c|c|c|c|c|c|c|c|c|c|c|c|c|}
\hline Fatty acids & 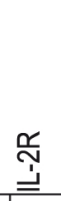 & $\stackrel{\sim}{\frac{N}{J}}$ & $\stackrel{n}{\stackrel{n}{\prime}}$ & $\stackrel{\circ}{\stackrel{\circ}{\prime}}$ & $\stackrel{\mathbb{N}}{\Sigma}$ & 芦 & $\begin{array}{l}\frac{\gamma}{\prime} \\
\frac{1}{\Sigma}\end{array}$ & $\begin{array}{l}\overline{1} \\
\frac{0}{\Sigma}\end{array}$ & $\frac{n}{\frac{n}{\prime}}$ & 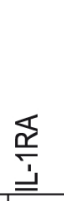 & $\stackrel{\infty}{\stackrel{\infty}{=}}$ & 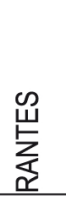 & 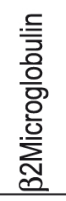 & 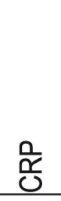 & 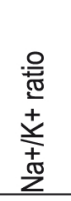 & $\begin{array}{l}\underset{丶}{\mathbb{X}} \\
\geqq \\
\geqq\end{array}$ \\
\hline $12: 0$ & 0.10 & 0.07 & 0.12 & 0.04 & 0.12 & -0.00 & 0.05 & 0.07 & 0.15 & -0.10 & -0.04 & 0.04 & 0.09 & -0.04 & 0.13 & 0.04 \\
\hline $14: 0$ & -0.08 & -0.11 & -0.07 & -0.04 & -0.06 & -0.21 & -0.19 & -0.11 & -0.10 & -0.24 & -0.22 & -0.18 & 0.09 & -0.14 & 0.22 & -0.01 \\
\hline $15: 0$ & 0.23 & 0.12 & 0.11 & 0.12 & 0.22 & 0.04 & 0.20 & 0.21 & 0.11 & -0.15 & 0.07 & 0.18 & -0.04 & -0.17 & 0.12 & -0.05 \\
\hline 16:0 & -0.03 & -0.07 & -0.18 & -0.18 & -0.17 & -0.16 & -0.12 & -0.12 & -0.16 & -0.27 & -0.03 & -0.06 & -0.26 & 0.16 & 0.03 & 0.06 \\
\hline $18: 0$ & 0.13 & -0.01 & -0.09 & -0.08 & 0.09 & 0.01 & 0.09 & 0.24 & 0.11 & -0.22 & 0.20 & 0.12 & -0.30 & 0.01 & -0.16 & -0.05 \\
\hline $20: 0$ & 0.23 & -0.03 & -0.14 & -0.08 & 0.12 & -0.11 & 0.06 & 0.25 & 0.07 & -0.24 & 0.12 & -0.18 & -0.29 & -0.09 & -0.19 & -0.10 \\
\hline $22: 0$ & 0.20 & 0.08 & -0.07 & -0.09 & 0.05 & -0.07 & -0.07 & 0.03 & 0.03 & 0.19 & 0.12 & -0.18 & -0.19 & 0.00 & -0.33 & -0.05 \\
\hline $24: 0$ & -0.06 & -0.04 & -0.05 & 0.05 & 0.02 & -0.03 & -0.18 & 0.01 & -0.17 & 0.02 & -0.14 & -0.28 & 0.04 & 0.02 & 0.02 & 0.11 \\
\hline Saturated FA & -0.12 & -0.21 & -0.16 & -0.23 & -0.16 & -0.19 & -0.22 & -0.13 & -0.09 & -0.42 & -0.14 & -0.15 & -0.20 & -0.05 & 0.02 & -0.10 \\
\hline $16: 1(n-7)$ & 0.19 & 0.30 & 0.20 & 0.16 & 0.14 & 0.03 & 0.24 & -0.18 & 0.11 & 0.12 & -0.16 & 0.20 & 0.35 & 0.18 & 0.25 & 0.30 \\
\hline $18: 1(n-7)$ cis & -0.02 & 0.24 & 0.35 & 0.36 & 0.09 & 0.15 & 0.13 & -0.07 & 0.08 & 0.13 & -0.11 & 0.17 & 0.45 & 0.11 & 0.26 & 0.41 \\
\hline $20: 1(n-7)$ & -0.28 & -0.02 & 0.14 & 0.07 & -0.18 & 0.10 & -0.26 & -0.14 & -0.12 & -0.08 & -0.27 & -0.20 & 0.21 & 0.02 & 0.01 & 0.11 \\
\hline MUFA n-7 & 0.09 & 0.29 & 0.27 & 0.25 & 0.09 & 0.07 & 0.18 & -0.19 & 0.06 & 0.13 & -0.20 & 0.17 & 0.43 & 0.16 & 0.28 & 0.36 \\
\hline $16: 1(n-9)$ & 0.23 & 0.33 & 0.37 & 0.34 & 0.39 & 0.18 & 0.35 & 0.06 & 0.27 & 0.14 & 0.12 & 0.24 & 0.33 & 0.11 & 0.16 & 0.29 \\
\hline $18: 1(n-9)$ cis & 0.15 & 0.26 & 0.22 & 0.24 & 0.21 & 0.18 & 0.30 & 0.06 & 0.13 & 0.12 & 0.16 & 0.35 & 0.10 & 0.18 & 0.08 & 0.21 \\
\hline $20: 1(n-9)$ & 0.55 & 0.46 & 0.23 & 0.12 & 0.41 & 0.07 & 0.37 & 0.24 & 0.33 & 0.20 & 0.15 & 0.02 & 0.19 & 0.07 & 0.14 & 0.20 \\
\hline MUFA n-9 & 0.17 & 0.27 & 0.23 & 0.24 & 0.23 & 0.19 & 0.31 & 0.05 & 0.14 & 0.11 & 0.14 & 0.36 & 0.11 & 0.20 & 0.09 & 0.22 \\
\hline $18: 3(n-3)$ & -0.24 & -0.26 & -0.02 & 0.07 & -0.11 & -0.10 & -0.10 & -0.04 & -0.14 & -0.05 & 0.03 & -0.16 & -0.04 & -0.16 & -0.01 & -0.17 \\
\hline $20: 3(n-3)$ & 0.01 & -0.19 & -0.44 & -0.47 & -0.19 & -0.38 & -0.21 & -0.02 & -0.22 & -0.07 & 0.10 & -0.41 & -0.39 & 0.05 & -0.45 & -0.27 \\
\hline $22: 5(n-3)$ & 0.16 & 0.31 & 0.43 & 0.36 & 0.17 & 0.32 & 0.30 & 0.22 & 0.31 & 0.29 & 0.09 & 0.16 & 0.24 & 0.08 & 0.06 & 0.31 \\
\hline $22: 6(n-3)$ & -0.10 & 0.12 & 0.16 & 0.13 & 0.03 & 0.04 & -0.00 & 0.03 & 0.09 & 0.16 & 0.04 & -0.06 & 0.19 & 0.05 & -0.09 & 0.16 \\
\hline PUFA n-3 & -0.24 & -0.19 & 0.04 & 0.09 & -0.09 & -0.01 & -0.09 & 0.03 & -0.05 & 0.01 & 0.06 & -0.11 & -0.04 & -0.12 & -0.09 & -0.13 \\
\hline $18: 2(n-6)$ cis & -0.01 & -0.03 & -0.07 & -0.00 & -0.03 & 0.01 & 0.01 & 0.08 & -0.04 & 0.31 & 0.07 & -0.01 & 0.01 & -0.09 & -0.17 & -0.13 \\
\hline $18: 3(n-6)$ cis & 0.10 & 0.13 & 0.16 & 0.11 & 0.05 & 0.02 & 0.03 & -0.05 & 0.07 & 0.24 & -0.03 & 0.11 & 0.08 & 0.07 & -0.38 & -0.01 \\
\hline $20: 2(n-6)$ & 0.37 & 0.37 & 0.34 & 0.24 & 0.26 & 0.37 & 0.25 & 0.40 & 0.32 & 0.35 & 0.02 & 0.13 & 0.24 & 0.02 & -0.01 & 0.09 \\
\hline $20: 3(n-6)$ & 0.30 & 0.31 & 0.39 & 0.32 & 0.23 & 0.23 & 0.26 & 0.18 & 0.29 & 0.23 & -0.10 & 0.14 & 0.26 & 0.15 & -0.13 & 0.16 \\
\hline $20: 4(n-6)$ & -0.03 & 0.11 & 0.29 & 0.19 & 0.03 & 0.25 & 0.19 & -0.06 & 0.22 & 0.24 & 0.00 & 0.06 & 0.25 & 0.26 & -0.14 & 0.24 \\
\hline $22: 4(n-6)$ & 0.02 & 0.08 & 0.11 & -0.00 & 0.01 & -0.04 & -0.15 & 0.06 & 0.01 & 0.00 & -0.11 & 0.03 & 0.04 & -0.13 & -0.33 & 0.03 \\
\hline PUFA n-6 & 0.01 & -0.00 & -0.03 & 0.03 & -0.01 & 0.05 & 0.03 & 0.11 & -0.00 & 0.32 & 0.08 & -0.02 & 0.04 & -0.08 & -0.16 & -0.12 \\
\hline $18: 1(n-9)$ trans & -0.19 & -0.07 & -0.09 & -0.04 & -0.13 & 0.07 & -0.04 & -0.03 & -0.03 & -0.12 & 0.14 & -0.04 & -0.08 & 0.12 & 0.02 & 0.05 \\
\hline $18: 2(n-6)$ trans & -0.26 & -0.09 & -0.01 & 0.00 & -0.06 & 0.05 & -0.14 & -0.06 & -0.10 & -0.09 & -0.06 & -0.20 & -0.02 & 0.05 & 0.02 & 0.12 \\
\hline Trans FA & -0.16 & $\begin{array}{r}-0.01 \\
\mathrm{~T} H \mathrm{He}\end{array}$ & $\begin{array}{l}-0.05 \\
\text { Ielper } 1 \mathrm{r}\end{array}$ & $\begin{array}{l}-0.04 \\
\text { related }\end{array}$ & -0.09 & 0.08 & $\begin{array}{r}-0.02 \\
\mathrm{~A}\end{array}$ & $\begin{array}{r}-0.02 \\
\text { anti bact }\end{array}$ & & -0.08 & $\begin{array}{l}0.09 \\
\text { In }\end{array}$ & $\begin{array}{r}-0.08 \\
\text { nflamma }\end{array}$ & $\begin{array}{l}-0.04 \\
\text { ation ma }\end{array}$ & $\begin{array}{r}0.13 \\
\text { arkers }\end{array}$ & 0.04 & 0.13 \\
\hline
\end{tabular}

the significant association of cis-vaccenic acid with higher risk of HIV MTCT. Surprisingly, we did not confirm the previously reported association between n-6 LC-PUFA and a lower risk of HIV MTCT [9]. In our study, the percentage of arachidonic acid was higher in the breast milk of women who transmitted HIV than in the group who did not. One explanation for this discrepancy may be the low magnitude of the differences in fatty acids and the very low percentage of some of them. Of note, we describe, a total of $n-$ 6 FA family approximately twice higher than the one reported by Villamor et al [9]. The enrichment of milk in n-6 FA observed in the present study conducted in KwaZulu-Natal, South Africa, could be attributed to local dietary habits (large intake of oil of corn, soybean or sunflower) since it was found in all three groups as previously discussed.

Interestingly we showed also correlations between percentages of FA and concentrations of immunological and inflammation factors in breast milk. Significant positive correlations were observed between several Th1 related cytokines (IL-12, IL-15, IP10) and MUFA such as cis-vaccenic and palmitoleic acid or PUFA such as dihomo- $\gamma$-linolenic (20:3n-6). By contrast we showed an inverse relationship between percentage of eicosatrienoic acid (20:3n-3) and concentration of Th1 related cytokines and inflammatory markers. This result is consistent with the recognized anti-inflammatory properties of dietary n-3 LC-PUFA [24]. The 
A

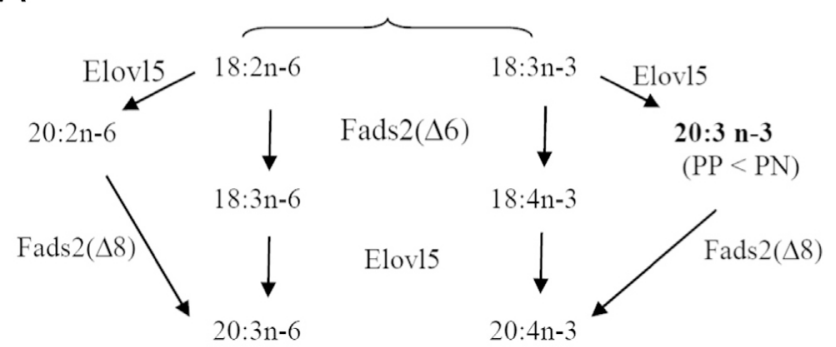

B

$16: 1 \mathrm{n}-7$

Elov15/(Elov16)

18:1n-7

$(\mathrm{PP}>\mathrm{PN})$

Fig. 1. Human fatty acids pathways of $A /$ PUFA n-6 and n-3 and B/ MUFA n-7 and n-9 (adapted from Guillou et al. [21]). FA with a difference between PP and PN groups are reported in bold face. Abbreviations: Fads: Fatty acid desaturase; Elovl: Elongase of very long chain fatty acids; PP: HIV-infected women with a postnatally HIV-1 infected infant; PN: HIV-infected women with a HIV-1 uninfected infant (PN).

percentage of eicosatrienoic acid correlated negatively with breast milk $\mathrm{Na}+/ \mathrm{K}+$ ratio while it was the opposite for cis-vaccenic acid. Breast milk $\mathrm{Na}+/ \mathrm{K}+$ ratio, indicative of subclinical mastitis, may be associated with MTCT of HIV, possibly via cell-associated HIV-1 shedding [25] although this hypothesis has not been confirmed [26]. Nevertheless, breast-milk $\mathrm{Na}+/ \mathrm{K}+$ ratio cannot explain the two present associations of cis-vaccenic acid or eicosatrienoic acid with MTCT of HIV because both associations persisted after adjustment for breast milk $\mathrm{Na}+/ \mathrm{K}+$ ratio. Lastly, eicosatrienoic acid exhibited a negative correlation with breast milk HIV-RNA while a positive correlation was observed with cis-vaccenic acid.

It is recognized that, dietary fish oil containing n-3 LC-PUFA are anti-inflammatory and modulates immune function through Th1 and Th2 cell polarization [24,27]. Although, FA-cytokine interactions in breast milk are poorly documented, FA could regulate the immunologic environment in breast milk, in addition to cytokines. In HIV-uninfected lactating mothers with and without allergic disease, the anti-inflammatory factor transforming growth factor (TGF) $\beta 2$ in breast milk was associated with n-6 PUFA, while it was inversely associated with saturated FA [13]. In healthy mothers, associations have been also reported between the percentage of docosahexaenoic acid, arachidonic acid, $\gamma$-linolenic acid, or EPA and concentrations of soluble immunologic factors: soluble CD14, TGF $\beta 1$, TGF $\beta 2$, and secretory IgA in breast milk [28]. However, the impact of cis-vaccenic acid on inflammatory and immune profile has not been documented so far, precluding any comparison to previous work.

Breast milk $\alpha$ - and $\beta$ - chemokines that induce T cell recruitment and activation in the mammary gland would encourage initiation of the viral cycle in latently infected CD4 T cells and rather promote ongoing viral replication [12]. In contrast, an antiviral Th-1 immune response environment in breast milk could limit HIV-1 replication [29,30]. High HIV-1 DNA levels in breast milk may be associated with an influx of leukocytes due to local or systemic inflammatory processes [31]. Hence, HIV replication in breast milk and HIV transmission through breastfeeding may be modulated by both breast milk lipids and cytokines components that mutually interact.

In the present study, milk was collected from both breasts, which enabled us to test whether findings were robust between the two breasts. Further, immune and inflammatory factors were measured, which allowed us to assess their association with FA. Determining the effect of HIV status on the immune and inflammatory breast milk profile is beyond the scope of this paper and will be addressed further. This study presents some limitations. The small case-control study did not allow adjustment for more than two factors and precluded us from investigating how inflammatory and immune soluble factors may have affected the association between FA and postnatal HIV MTCT. Because of the observational design, we did not correct type-1 error rate for multiple testing. Then, associations of cis-vaccenic and eicosatrienoic acids with postnatal transmission of HIV through breastfeeding may be only statistical and not causative, though breast milk was sampled immediately, before infant HIV infection. Also, maternal diet data were not collected and we did not assess plasma FA composition, which could have fueled our hypotheses.

In conclusion, this case-control study suggested a potential association between breast milk FA profile and HIV-1 transmission through breastfeeding. For the first time an inverse relationship between a n-3 LC-PUFA (eicosatrienoic acid) in breast milk and postnatal HIV-1 MTCT was reported. In parallel, an opposite association was observed with a n-7 MUFA (cis-vaccenic acid) that appeared deleterious. Significant correlations between percentages of FA and cytokines, inflammatory markers and HIV RNA in breast milk are consistent with these findings. The issue of a potential causal role of FA in breastfeeding HIV transmission needs to be confirmed in a large prospective cohort.

\section{Contributions}

E. Tuaillon, P. van de Perre and D. Neveu designed the study; ML. Newell provided access to breast milk samples; S. Badiou, E. Tuaillon and J. Viljoen conducted research including biochemical analyses (S. Badiou); immune factors assays (E. Tuaillon) and virology measurements (J Viljoen). JB. Escudié and D. Neveu performed statistical analysis. S. Badiou, E. Tuaillon and D. Neveu wrote the first draft of the paper that was reviewed/edited by JP. Cristol, P. van de Perre, ML. Newell and J. Viljoen. All authors read and approved the final manuscript and have equal responsibility for final content.

\section{Financial support}

The study was funded by INSERM-Agence Nationale de Recherche sur le SIDA et les hépatites- grant ANRS 1271. This funder has no role in the design, analysis or writing of the present manuscript. 


\section{References}

[1] WHO/UNAIDS/UNICEF. Infant feeding guidelines In. Geneva, Switzerland: WHO/UNAIDS, 2013.

[2] H.M. Coovadia, E.R. Brown, M.G. Fowler, T. Chipato, D. Moodley, K. Manji, et al., Efficacy and safety of an extended nevirapine regimen in infant children of breastfeeding mothers with HIV-1 infection for prevention of postnatal HIV-1 transmission (HPTN 046): a randomised, double-blind, placebo-controlled trial, Lancet 379 (2012) 221-228.

[3] The Kesho Bora Study Group, Triple antiretroviral compared with zidovudine and single-dose nevirapine prophylaxis during pregnancy and breastfeeding for prevention of mother-to-child transmission of HIV-1 (Kesho Bora study): a randomised controlled trial, Lancet Infect. Dis. 11 (2011) 171-180.

[4] R.M. Lawrence, C.A. Pane, Human breast milk: current concepts of immunology and infectious diseases, Curr. Probl. Pediatr. Adolesc. Health Care 37 (2007) 7-36.

[5] A. Wahl, M.D. Swanson, T. Nochi, R. Olesen, P.W. Denton, M. Chateau, et al., Human breast milk and antiretrovirals dramatically reduce oral HIV-1 transmission in BLT humanized mice, PLoS Pathog. 8 (2012) e1002732.

[6] M.A. Lyimo, A.L. Howell, E. Balandya, S.K. Eszterhas, R.I. Connor, Innate factors in human breast milk inhibit cell-free HIV-1 but not cell-associated HIV-1 infection of CD4+ cells, J. Acquir. Immune Defic. Syndr. 51 (2009) 117-124.

[7] J. Ndirangu, J. Viljoen, R.M. Bland, S. Danaviah, C. Thorne, P. Van de Perre, et al., Cell-free (RNA) and cell-associated (DNA) HIV-1 and postnatal transmission through breastfeeding, PLoS One 7 (2012) e51493.

[8] D. Neveu, J. Viljoen, R.M. Bland, N. Nagot, S. Danaviah, A. Coutsoudis, et al., Cumulative exposure to cell-free HIV in breast milk, rather than feeding pattern per se, identifies postnatally infected infants, Clin. Infect. Dis. 52 (2011) 819-825.

[9] E. Villamor, I.N. Koulinska, J. Furtado, A. Baylin, S. Aboud, K. Manji, et al., Longchain n-6 polyunsaturated fatty acids in breast milk decrease the risk of HIV transmission through breastfeeding, Am. J. Clin. Nutr. 86 (2007) 682-689.

[10] C.N. Serhan, Systems approach to inflammation resolution: identification of novel anti-inflammatory and pro-resolving mediators, J. Thromb. Haemost. 7 (Suppl 1) (2009) S44-S48.

[11] P.C. Calder, R.F. Grimble, Polyunsaturated fatty acids, inflammation and immunity, Eur. J. Clin. Nutr. 56 (Suppl 3) (2002) S14-S19.

[12] P. Van de Perre, P.A. Rubbo, J. Viljoen, N. Nagot, T. Tylleskar, P. Lepage, et al., HIV-1 reservoirs in breast milk and challenges to elimination of breast-feeding transmission of HIV-1, Sci. Transl. Med. 4 (2012) 143 sr143.

[13] K. Laiho, A.M. Lampi, M. Hamalainen, E. Moilanen, V. Piironen, T. Arvola, et al., Breast milk fatty acids, eicosanoids, and cytokines in mothers with and without allergic disease, Pediatr. Res. 53 (2003) 642-647.

[14] R. Bland, H. Coovadia, A. Coutsoudis, N. Rollins, M. Newell, Cohort profile: mamanengane or the Africa centre vertical transmission study, Int. J. Epidemiol. 39 (2010) 351-360.

[15] H.M. Coovadia, N.C. Rollins, R.M. Bland, K. Little, A. Coutsoudis, M.L. Bennish, et al., Mother-to-child transmission of HIV-1 infection during exclusive breastfeeding in the first 6 months of life: an intervention cohort study, Lancet 369 (2007) 1107-1116.
[16] Rouet, Impact of HIV-1 genetic diversity on plasma HIV-1 RNA Quantification: usefulness of the Agence Nationale de Recherches sur le SIDA secondgeneration long terminal repeat-based real-time reverse transcriptase polymerase chain reaction test, J. Acquir. Immune Defic. Syndr. 45 (2007) 380-388.

[17] M.K. Ghosh, L. Kuhn, J. West, K. Semrau, D. Decker, D.M. Thea, et al., Quantitation of human immunodeficiency virus type 1 in breast milk, J. Clin. Microbiol. 41 (2003) 2465-2470.

[18] R.M. Bland, R. Becquet, N.C. Rollins, A. Coutsoudis, H.M. Coovadia, M.L. Newell, Breast health problems are rare in both HIV-infected and HIV-uninfected women who receive counseling and support for breast-feeding in South Africa, Clin. Infect. Dis. 45 (2007) 1502-1510.

[19] B. Koletzko, I. Thiel, P.O. Abiodun, The fatty acid composition of human milk in Europe and Africa, J. Pediatr. 120 (1992) S62-S70.

[20] F. Marangoni, C. Agostoni, A.M. Lammardo, M. Bonvissuto, M. Giovannini, C. Galli, et al., Polyunsaturated fatty acids in maternal plasma and in breast milk, Prostaglandins Leukot. Essent. Fat. Acids 66 (2002) 535-540.

[21] H. Guillou, D. Zadravec, P.G. Martin, A. Jacobsson, The key roles of elongases and desaturases in mammalian fatty acid metabolism: Insights from transgenic mice, Prog. Lipid Res. 49 (2010) 186-199.

[22] T.A. Burns, A.K. Kadegowda, S.K. Duckett, S.L. Pratt, T.C. Jenkins, Palmitoleic (16:1 cis-9) and cis-vaccenic (18:1 cis-11) acid alter lipogenesis in bovine adipocyte cultures, Lipids 47 (2012) 1143-1153.

[23] S. Tripathy, D.B. Jump, Elovl5 regulates the mTORC2-Akt-FOXO1 pathway by controlling hepatic cis-vaccenic acid synthesis in diet-induced obese mice, J. Lipid Res. 54 (2013) 71-84.

[24] P.C. Calder, Dietary modification of inflammation with lipids, Proc. Nutr. Soc. 61 (2002) 345-358.

[25] S. Kantarci, I.N. Koulinska, S. Aboud, W.W. Fawzi, E. Villamor, Subclinical mastitis, cell-associated HIV-1 shedding in breast milk, and breast-feeding transmission of HIV-1, J. Acquir. Immune Defic. Syndr. 46 (2007) 651-654.

[26] K.M. Lunney, P. Iliff, K. Mutasa, R. Ntozini, L.S. Magder, L.H. Moulton, et al., Associations between breast milk viral load, mastitis, exclusive breast-feeding, and postnatal transmission of HIV, Clin. Infect. Dis. 50 (2010) 762-769.

[27] S. Endres, S.N. Meydani, R. Ghorbani, R. Schindler, C.A. Dinarello, Dietary supplementation with n-3 fatty acids suppresses interleukin-2 production and mononuclear cell proliferation, J. Leukoc. Biol. 54 (1993) 599-603.

[28] H.J. Urwin, J. Zhang, Y. Gao, C. Wang, L. Li, P. Song, et al., Immune factors and fatty acid composition in human milk from river/lake, coastal and inland regions of China, Br. J. Nutr. 109 (2013) 1949-1961.

[29] S. Sabbaj, B.H. Edwards, M.K. Ghosh, K. Semrau, S. Cheelo, D.M. Thea, et al., Human immunodeficiency virus-specific CD8 $(+)$ T cells in human breast milk, J. Virol. 76 (2002) 7365-7373.

[30] S. Sabbaj, M.K. Ghosh, B.H. Edwards, R. Leeth, W.D. Decker, P.A. Goepfert, et al., Breast milk-derived antigen-specific CD8 + T cells: an extralymphoid effector memory cell population in humans, J. Immunol. 174 (2005) 2951-2956.

[31] F. Hassiotou, A.R. Hepworth, P. Metzger, C. Tat Lai, N. Trengove, P.E. Hartmann, et al., Maternal and infant infections stimulate a rapid leukocyte response in breastmilk, Clin. Transl. Immunol. 2 (2013) e3. 